\title{
Upaya Meningkatkan Penjualan Minyak Kayu Putih Ruu Dengan Metode Marketing Mix, Berdasarkan Analisis SWOT Dan STP Di Wasur Kabupaten Merauke
}

\author{
Muhamad Ibnu Baha Udin ${ }^{1, *}$, Dayal Gustopo ${ }^{2}$, Ellysa Nursanti ${ }^{3}$ \\ Program Studi Teknik Industri, Fakultas Teknologi Industri, Institut Teknologi Nasional Malang \\ *E-mail: muhamadibnu22@gmail.com
}

\begin{abstract}
Abstrak
Kelompok penyuling kayu putih merupakan salah satu UKM yang terletak di daerah Wasur kabupaten Merauke dan memproduksi minyak kayu putih jenis Astromyrthus sympiocarpa yang diberi nama Ruu. Hasil produksi minyak kayu putih Ruu dipasarkan sekitar kampung Wasur dan belum diserap pasar secara maksimum. Tujuan penelitian untuk dapat memetakan posisi UKM minyak kayu putih Ruu dan pasar sasaran yang nantinya dapat meningkatkan penjualan. Hasil penelitian analisis SWOT menunjukan bahwa Ruu berada pada posisi Diversifikasi. Selanjutnya untuk analisis STP (Segmentation, Targeting, dan Positioning) menghasilkan targetinguntuk minyak kayu putih Ruu yaitu jenis kelamin perempuan, kisaran usia antara 17-22 tahun dan memiliki pekerjaan sebagai pelajar/ mahasiswa yang berada pada daerah wilayah kabupaten Merauke. Sedangkan untuk positioning produk Ruu berada diposisi market follower. Pada analisis marketing mix $4 \mathrm{P}$ ini produk tetap menjaga kualitas dan pengemasan menggunakan botol plastik, sehingga Ruu dapat mengikuti harga pesaing sesuai ukuran botol, memberikan potongan harga dan pemberian komisi bagi agen perantara yang memasarkan produk Ruu. Maka untuk distribusi mengadakan kerjasama dengan agen perantara yang dapat mengantarkan produk Ruu dengan cepat dan tepat waktu serta promosi dapat dilakukan melalui media sosial.
\end{abstract}

Kata Kunci : Minyak Kayu Putih Ruu, Marketing Mix, Segmentasi Pasar, STP, SWOT

\section{Pendahuluan}

Minyak kayu putih di Indonesia telah lama dilakukan dalam skala industri baik industri rumah tangga maupun industri besar. Selama ini jenis Melaleuca cajuputi sspmerupakan jenis utama yang dikembangkan sebagai bahan baku minyak kayu putih di Indonesia disebabkan kadar sineolnya yang tinggi[1].Kabupaten Merauke sebagai tempat dimana pohon kayu putih tumbuh dengan sendirinya. Maka tentunya menyimpan potensi besar untuk menunjang kegiatan perekonomian masyarakat lokal khusunya dan harapan ke depan dapat menjadi salah satu ciri khas kota Merauke. Kelompok penyuling kayu putih merupakan salah satu UKM yang terletak di daerah Wasur kabupaten Merauke dan memproduksi minyak kayu putih jenis Astromyrthus sympiocarpa yang diberi nama Ruu dalam bahasa suku Marorimenggey, yang artinya minyak kayu. Hasil produksi minyak kayu putih Ruu dipasarkan sekitar area produksi. Adapun kendala dalam pemasaran dan kurang kerjasama atau perhatian pihakpihak dari kalangan dunia usaha, pemerintah dan masyarakat umum lain sehingga dibutuhkan strategi dalam melakukan pemasaran agar dapat memetakan posisi dan pasar sasaran yang nantinya dapat meningkatkan penjualan[2].

Penelitian ini bertujuan untuk meningkatkan penjualan minyak kayu putih Ruu dengan menggunakan metode marketing mix berdasarkan analisis SWOT agar dapat memetakan posisi UKM minyak kayu putih Ruu serta analisis STP (Segmentation, Targeting dan Positioning)[3] untuk mendapatkan fokus segmentasi pasar sasaran. 


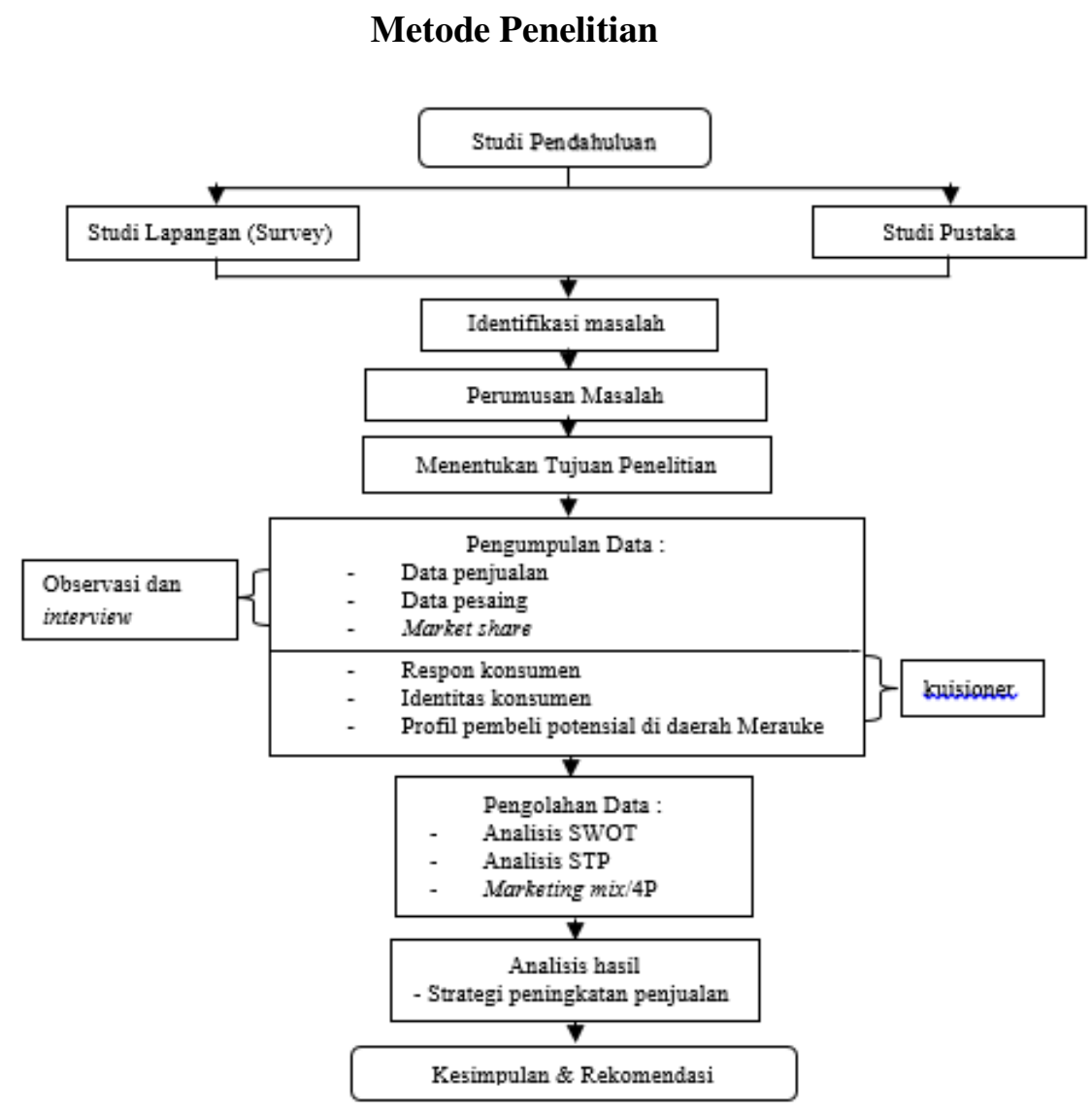

Gambar 1 Diagram Alir Penelitian

Pada Gambar 1, disampaikan bahwapengumpulan datadilakukan dengan cara observasi dan wawancara. Kuesioner juga digunakan sebagai instrument penelitian.Pengolahan data hasil kuesioner digunakan untuk mendapatkan posisi SWOT, marketing mix, dan STP sebagai strategi usulan penelitian.

\section{Hasil dan Pembahasan}

Kuesioner digunakan untuk dapat menggali situasi kondisi terkini Ruu dan memetakannya pada matriks SWOT [4]. Tabel 1, 2, 3, dan 4 menyatakan berisi pernyataan Kekuatan, Kelemahan, Peluang dan Ancaman [5]. Tabel juga berisi bobot, rating dan value. Bobot diperoleh dari Expert, dalam hal ini adalah pemilik dan pelaku usaha. Rating diperoleh dari jawaban responden. Value diperoleh dari perkalian bobot dan rating. Terlihat pada Tabel 1, hasil rekapitulasi kuisionermaka value tertinggi ada pada pernyataan kedua, dengan nilai value 1,00 dan total value pada pernyataan Kekuatan diperoleh 2,00 .

Tabel 1 Pernyataan Kekuatan

\begin{tabular}{llccc}
\hline No & \multicolumn{1}{c}{ A. Pernyataan Kekuatan (Strength) } & Bobot & Rating & Value \\
\hline 1 & Hasil produksi penyulingan minyak kayu putih Ruu dalam kuantitas banyak & 0,20 & 2 & 0,40 \\
2 & Ruu selektif dalam pemilihan bahan baku & 0,50 & 2 & 1,00 \\
3 & UKM Ruu menjual hasil penyulingan langsung ditempat produksinya & 0,30 & 2 & 0,60 \\
\hline TOTAL & 1,00 & & 2,00 \\
\hline
\end{tabular}

Terlihat pada Tabel 2, hasil rekapitulasi kuisioner maka value tertinggi ada pada pernyataan pertama, dengan nilai value 0,36 dan total value pada pernyataan Kelemahan diperoleh 1,48. 
Tabel 2 Pernyataan Kelemahan

\begin{tabular}{|c|c|c|c|c|}
\hline \multicolumn{2}{|r|}{ No B. Pernyataan Kelemahan (Weakness) } & Bobot & Rating & Value \\
\hline 1 & Merk/ brended minyak kayu putih Ruu belum terkenal di daerah Merauke & 0,18 & 2 & 0,36 \\
\hline 2 & Desain stiker Ruu kurang menarik & 0,15 & 2 & 0,30 \\
\hline 3 & Minyak kayu putih Ruu kemasan botol kurang menarik & 0,19 & 1 & 0,19 \\
\hline 4 & Harga minyak kayu putih Ruu terlalu mahal & 0,15 & 2 & 0,30 \\
\hline 5 & Ruu mempuyai satu jenis produk & 0,20 & 1 & 0,20 \\
\hline 6 & Pelayanan penjualan produk Ruu belum dilakukan baik terhadap konsumen & 0,13 & 1 & 0,13 \\
\hline \multicolumn{2}{|r|}{ TOTAL } & 1,00 & & 1,48 \\
\hline
\end{tabular}

Terlihat pada Tabel 3, hasil rekapitulasi kuisioner maka value tertinggi ada pada pernyataan pertama, dengan nilai value 0,46 dan total value pada pernyataan Peluang diperoleh 2,00.

Tabel 3 Pernyataan Peluang

\begin{tabular}{llcrc}
\hline No & \multicolumn{1}{c}{ C. Pernyataan Peluang (Opportunities) } & Bobot & Rating & Value \\
\hline 1 & Meningkatnya kebutuhan masyarakat terhadap minyak kayu putih & 0,23 & 2 & 0,46 \\
2 & Media promosi yang luas dan menarik & 0,20 & 2 & 0,40 \\
3 & Banyak pasar modern di kabupaten Merauke & 0,22 & 2 & 0,44 \\
4 & Memberikan aromaterapi pada produk minyak kayu putih Ruu & 0,16 & 2 & 0,32 \\
5 & Alternatif pengembangan kemasan yang menarik & 0,19 & 2 & 0,38 \\
\hline TOTAL & 1,00 & & 2,00 \\
\hline
\end{tabular}

Terlihat pada Tabel 4, hasil rekapitulasi kuisioner maka value tertinggi ada pada pernyataan kedua, dengan nilai value 2,45 dan total value pada pernyataan Kekuatan diperoleh 3,55.

Tabel 4 Pernyataan Ancaman

\begin{tabular}{llccc}
\hline No & D. Pernyataan Ancaman (Threats) & Bobot & Rating & Value \\
\hline 1 & Banyaknya pesaing produk minyak kayu putih lain & 0,55 & 2 & 1,10 \\
2 & Gencarnya promosi produk/ merk pesaing & 0,45 & 2 & 2,45 \\
\hline TOTAL & 1,00 & & 3,55 \\
\hline
\end{tabular}

a. Diagram Analisis SWOT

Dari perhitungan pembobotan analisa situasi atau lingkungan internal dan eksternal UKM penyulingan minyak kayu putih Ruu dapat diketahui total masing-masing pernyataan dari perhitungan dengan analisa SWOT adalah sebagai berikut:

- Pernyataan Kekuatan (Strengths) total skor =2,00

- Pernyataan Kelemahan (Weaknesses) total skor =1,48

- Pernyataan Peluang (Opportunities) total skor $=2,00$

- Pernyataan Ancaman (Threats) total skor =3,55

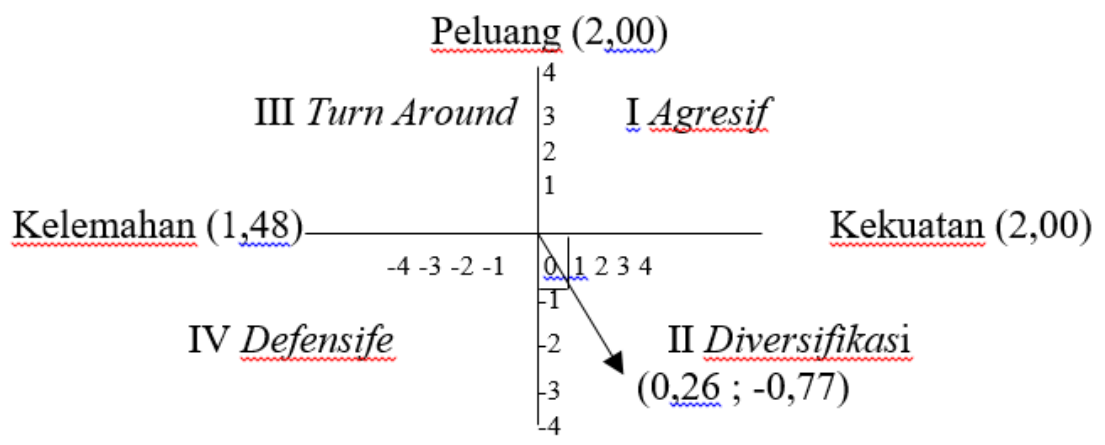

Ancaman (3,55)

Gambar 2 Diagram SWOT

Pada Gambar 2 titik koodinat dari perhitungan tersebut, maka skor untuk variabel kekuatan menjadi $(+2,00)$ dan total skor peluang menjadi $(+2,00)$, sedangkan perhitungan untuk total skor variabel kelemahan dan ancaman menjadi $(-1,48)$ dan $(-3,55)$.Sehingga hasil analisis SWOT, memetakan posisi UKM minyak kayu putih Ruu terletak pada kuadran II yaitu Diversifikasi. 


\section{STP (Segmentation, Targeting, Positioning)}

Pengelompokan yang baik harus dilakukan dengan prosedur yang tepat [6].

\section{a. Segmentation}

Proses pengelompokan pasar keseluruhan yang heterogen menjadi kelompok - kelompok yang memiliki kesamaan dalam hal kebutuhan, perilaku dan respon terhadap program pemasaran[7].

1) Jenis kelamin responden

Tabel 5Jenis Kelamin Responden

\begin{tabular}{lcc}
\hline Jenis kelamin & Jumlah responden & Persentase \\
\hline Laki-laki & 25 & $42 \%$ \\
Perempuan & 35 & $58 \%$ \\
\hline
\end{tabular}

2) Usia responden

Tabel 6 Usia Responden

\begin{tabular}{lcc}
\hline Umur Jumlah & responden & Persentasi \\
\hline$<17$ tahun & - & - \\
$17-22$ tahun & 27 & $45 \%$ \\
$22-27$ tahun2135\% & & \\
$27-32$ tahun813\% & & \\
$>32$ tahun 4 & & $7 \%$ \\
\hline
\end{tabular}

3) Jenis pekerjaan responden

Tabel 7 Jenis Pekerjaan Responden

\begin{tabular}{lcc}
\hline Pekerjaan & Jumlah responden & Persentasi \\
\hline Pelajar/ mahasiswa & 34 & $57 \%$ \\
Guru dan dosen & 8 & $13 \%$ \\
Wiraswasta & 3 & $5 \%$ \\
Swasta & 2 & $3 \%$ \\
Tani & 7 & $12 \%$ \\
Ibu rumah tangga & 6 & $10 \%$ \\
\hline
\end{tabular}

4) Pendidikan responden

Tabel 8 Pendidikan Responden

\begin{tabular}{lcc}
\hline Pendidikan & Jumlah responden & Persentasi \\
\hline SD & 7 & $12 \%$ \\
SMP & 12 & $20 \%$ \\
SMA & 23 & $38 \%$ \\
Sarjana & 18 & $30 \%$ \\
\hline
\end{tabular}

5) Asal daerah responden

Penyebaran kuesioner disebarkan di daerah kabupaten Merauke, adapun responden kuesioner berasal dari beberapa provinsi atau luar pulau yang sudah menetap di kabupaten Merauke.

\section{b. Targeting}

Proses pengevaluasian segmentasi dan pemfokusan segmentasi pemasaran pada sekelompok orang yang memiliki potensi untuk memberikan respon[8].

1) Jenis Kelamin: Perempuan

2) Usia Konsumen: 17 - 22 tahun

3) Jenis Pekerjaan: Pelajar/ Mahasiswa

4) Asal daerah: Wilayah kabupaten Merauke

\section{c. Positioning}

Suatu usaha perusahaan untuk memberikan gambaran (image) didalam pikiran konsumen ketika melihat atau mendengar tentang produk atau brand dari perusahaan tersebut[9]. Produk Ruu menempati posisi sebagai Market Follower. Ruu belum dapat bersaing dengan pemain-pemain nasional, karena keterbatasan modal dan kemampuan Sumber Daya Manusia yang dimiliki. 
Disamping itu, Ruu belum dapat menjaga stabilitas produksinya. Hal inilah yang menjadi alasan mengapa saat ini Ruu masih berada di posisi Market Follower.

Analisis Marketing Mix, Menurut Kotler, marketing mix adalah seperangkat alat pemasaran yang digunakan perusahaan untuk terus-menerus mencapai tujuan pemasarannya di pasar sasaran[10]. Adapun rumusan alternatif usulan strategi pemasaran yang tepat bagi produk Ruu dengan marketing mix, antara lain sebagai berikut:

\section{a. Product (Produk)}

Produk merupakan segala sesuatu yang dapat menghasilkan kepuasan bagi pemakainya. Adapun langkah-langkah yang harus dilakukan oleh produk Ruu dalam menjaga kualitas produk dan memenuhi keinginan dari konsumen antara lain adalah sebagai berikut:Penetapan standar mutu, pemilihan bahan baku yang selektif untuk menjaga kualitas yang ada pada produk Ruu dengan cara tidak menerima bahan baku yang tidak sesuai dengan standar mutu untuk diproses selanjutnya. Sedangkan untukkemasan melakukan mengemasan dengan botol yang sama dengan pasaran yaitu botol plastik. Hal ini bertujuan untuk mebuat kemasan dari minyak kayu putih Ruu lebih ringan ketika dibawa dan membuat harga produksi tidak terlalu besar.

\section{b. Price (Harga)}

Harga merupakan komponen penting yang harus dipikirkan secara detail oleh pengusaha. Maka langkah yang harus dilakukan yaitu dengan cara:Pemberian potongan harga atau diskon kepada konsumen yang membeli produk-produk Ruu dalam jumlah yang besar dan memberikan potongan harga kepada konsumen yang bersedia membeli produk dalam keadaan tidak sempurna (cacat). Selanjutya pemberian hadiah atau komisi yaitu memberikan komisi atau hadiah kepada agen perantara dengan prosentase yang telah ditetapkan perusahaan. Hal ini nantinya menarik para perantara untuk ikut serta dalam memasarkan produk Ruu ke konsumen lainnya.

\section{c. Place (Distribusi atau Tempat)}

Saluran distribusi sangat dibutuhkan bagi penyaluran produk dari produsen hingga sampai ke tanggan konsumen akhir. Produk Ruu dalam penjualannya hanya mengandalkan penjualan secara langsung atau langsung jual di tempat jadi tidak ada pengiriman produk ke beberapa daerah dan kota yang menjadi daerah tujuan dari pemasarannya. Untuk itu produk Ruu perlu memiliki karyawan khusus yang menangani tentang penyaluran produk yang berada di dalam kota serta melakukan kerjasama dengan agen perantara yang dapat mengantarkan produk-produknya dengan cepat dan tepat waktu sehingga dapat terjalin hubungan yang harmonis antara produsen dan konsumen.

\section{d. Promotion (Promosi)}

Promosi merupakan komunikasi yang bertujuan untuk mengkonfirmasikan suatu produk perusahaan kepada masyarakat. Adapun usulan strategi pemasaran melalui promosi yang dapat dilakukan oleh UKM dari produk Ruu, antara lain sebagai berikut:Penjualan perseorangan (Personal Selling)yaitu jika sebelumnya dalam penjualan produk Ruu hanya mengandalkan penjualan secara langsung atau melakukan proses jual beli di daerah kampung wasur, maka seharusnya diadakan promosi melalui personal selling melalui media telephone oleh UKM dalam rangka mempromosikan produknya yaitu melalui media online seperti email atau media social lainnya yang mendukung. Dengan cara seperti itu dapat mudah menawarkan produk yang dihasilkannya kepada konsumen secara luas dan bebas, dengan media ini UKM dapat melakukan kegiatan seperti tawar menawar harga, pemesanan produk, serta menerima kritik dan saran dari konsumen.Selanjutnyapromosi penjualan (Sales Promotion)yaitupromosi penjualan produk Ruu dapat dilakukan dengan cara mengikuti event-event dan lomba yang diadakan oleh pemerintah setempat ataupun event-event luar di masyarakat, sehingga dengan mengikuti kegiatan tersebut dapat secara tidak langsung memperkenalkan produk Ruu kepada masyarakat luas dan dapat menarik perhatian konsumen yang menyaksikannya.Sedangkandalam publisitas produk Ruu tidak ada upaya yang dilakukan dalam mempromosikan produknya menggunakan media online, sehingga penjualan produk Ruu dirasa masih kurang maksimal. Oleh karena itu, perlu diadakan upaya 
peningkatan promosi melalui media social lainnya seperti facebook, twitter, blog, website, WA, BBM, dll. Dengan media promosi tersebut produk Ruu dapat selalu memberikan informasi mengenai produk yang diproduksinya serta promo-promo yang diberikan untuk para konsumen minyak kayu putih.

\section{Kesimpulan}

Berdasarkan penelitian yang telah dilakukan mengenai "upaya meningkatkan penjualan minyak kayu putih Ruu dengan metode marketing mix, berdasarkan analisis SWOT dan STP di Wasur kabupaten Merauke", dapat di simpulkan sebagai berikut:Memetakan posisi UKM penyulingan minyak kayu putih Ruu dalam SWOT terletak pada kuadran II (Diversifikasi), sedangkan penggunaan produk Ruu didominasi oleh kaum perempuan berumur 17-22 tahun dengan pekerjaan pelajar/ mahasiswa yang target penjualannya didaerah Merauke dan UKM Ruu memposisikan dirinya pada strategi market follower.Bauran pemasaran (Marketing Mix) sebagai strategi yang tepat untuk meningkatkan penjualan minyak kayu putih Ruu dengan melihat aspek 4P, melalui product tetap menjaga kualitas dan pengemasan dalam botol plastik sesuai pesaing lain. Sedangkan untuk price, memberikan potongan harga, mengikuti harga pesaing dengan menyesuaikan ukuran kemasan (botol) dan memberikan komisi kepada agen perantara. Selanjutnya untuk distribusi, yakni menangani tentang penyaluran produk serta melakukan kerjasama dengan agen yang dapat mengantarkan produk Ruu dengan cepat dan tepat. Sedangkan untuk promosi perlu diadakan upaya peningkatan promosi melalui media sosial seperti faebook, twitter, blog, website, WA, dan BBM.

\section{Daftar Referensi}

[1] Hatta, S. Budidaya dan Penyulingan Kayu Putih. Yogyakarta: Kanisiu. 2003 [online]. Avaible: http://ojs.unud.ac.id/index.php/agribisnis/article/viewFile/7909/5990

[2] Putri Paramitha E, Djunaidi. Much, Al-Ghofari A. Kholid, "Analisis SWOT Sebagai Strategi Meningkatkan Daya Saing Pada Bisnis Usaha Batik". [online]. Available: http://eprints.ums.ac.id/35575/1/02.\%20Naskah\%20Publikasi\%20Elysa.pdf

[3] Kotler, P, Armstrong, G, Prinsip-prinsip Pemasaran Jilid 1 [8th ed.], Jakarta: Erlangga. 2001

[4] David, Fred R. Strategic Manajement: Manajemen Strategis, Edisi 10. Jakarta: Salmeba Empat. 2006

[5] ouhuwat Ronaldo, Ambarawati Igaa, dan Iw. Arga, "Prospek Pengembangan Agribisnis Minya Kayu Putihdi Kecamatan Seram Barat, Kabupaten Seram Bagian Barat," Jurnal Manajemen Agribisnis Vol.1, No.1. Mei 2013.

[6] Kasali, R. Membidik Pasar Indonesia Segmenting, Targeting dan Positioning. Gramedia. Jakarta, 2001.

[7] Tjiptono, Fandi. Strategi Pemasaran. Penerbit Andi. Yogyakarta. 2006.

[8] Keegan \& Green. Global Marketing. Edisi 5. Penerbit London Pearson education. 2008.

[9] Kotler \& Keller, Manajemen Pemasaran jilid 1 (edisi 13), Jakarta: Erlangga, 2008.

[10] Kotler, P, \& Keller K L. Manajemen Pemasaran. PT. Indeks. Jakarta, 2008. 